\title{
Arterial blood supply of hepatocellular carcinoma is associated with efficacy of sorafenib therapy
}

\author{
Xiang-Hua Zhang ${ }^{1}$, Qian Zhu ${ }^{2}$, Jing $\mathrm{Li}^{1}$, Liang Huang ${ }^{1}$, Jian-Jun $\mathrm{Yan}^{1}$, Feng $\mathrm{Xu}^{1}$, \\ Jun $\mathbf{L i}^{1}$, Yi-Qun Yan ${ }^{1}$
}

${ }^{1}$ Department of Hepatic Surgery I, Eastern Hepatobiliary Surgery Hospital, Second Military Medical University, Shanghai 200438, China. ${ }^{2}$ Department of Hepatobiliary Surgery, Jingmen First People's Hospital, Jingmen 448000, Hubei, China.

\begin{abstract}
Aim: There are some previous reports concerning the relationship between prognosis of patients treated with sorafenib and parameters of computed tomography (CT) and magnetic resonance imaging (MRI). This study presents monocentric experience with sorafenib in the treatment of hepatocellular carcinoma (HCC) patients and will try to identify predictive factors for survival based on the correlation of results from imaging and survival. Methods: A total of $38 \mathrm{HCC}$ patients treated from April 2009 to December 2010 with sorafenib were included in this study. HCCs were classified as good arterial supply and poor arterial supply according to the enhancement intensity on CT scan or MRI. Clinical data were collected and survival time was analyzed by Kaplan-Meier method. A Cox's regression model was performed to reveal predictive factors for survival. Results: Among the 38 patients treated with sorafenib, mean age was $53.3 \pm 11.1$ years and $35(92.1 \%)$ were males. Tumors in 17 patients were classified as good arterial supply, while the remaining 21 patients belonged to poor arterial supply. The median survival time (MST) was 10.7 months [95\% confidence interval (Cl), 8.7-12.7] and the 1-year overall survival (OS) was $41.0 \%$. The MST and 1-year OS in patients with a good arterial supply of tumors were 12 months (range: 4-20 months) and $52.9 \%$, compared with that of 7 months (range: $1-16$ months) and $23.8 \%$ in patients with a poor arterial supply of tumors $(P=$ 0.002). Patients who had tumors at Barcelona Clinic Liver Cancer (BCLC) stage B had longer MST and higher OS than those who had tumors at BCLC stage $\mathrm{C}$, but there was no statistical difference between these two stages. On multivariate analysis, only arterial supply of the tumors remained statistically predictive for OS (hazard ratios $0.22,95 \% \mathrm{Cl}, 0.07-0.67, P=0.008$ ). Conclusion: Arterial blood supply is an independent predictor for survival in patients treated with sorafenib, and patients with a good arterial supply of tumors benefit more than those with a poor arterial supply of tumors.
\end{abstract}

Key words: Arterial blood supply; hepatocellular carcinoma; sorafenib

\section{Address for correspondence:}

Prof. Yi-Qun Yan, Department of Hepatic Surgery I, Eastern Hepatobiliary Surgery Hospital, Second Military Medical University, Shanghai 200438, China. E-mail: ehbhyyq@163.com

Received: 09-07-2015, Accepted: 09-11-2015

\section{INTRODUCTION}

Hepatocellular carcinoma (HCC) is the sixth most common cancer and the third most frequent cause of cancer-related death. ${ }^{[1]}$ Only about $15 \%$ patients with HCC are suitable for curative treatment, such as

\begin{tabular}{|l|c|}
\hline \multicolumn{3}{|c|}{ Access this article online } \\
\hline \multirow{2}{*}{ Website: } & Quick Response Code \\
http://hrjournal.net & \\
\hline & DOI: \\
10.4103/2394-5079.170542 & \\
\end{tabular}

surgical therapy (resection and liver transplantation) and locoregional therapy (radiofrequency ablation). For patients with advanced HCC, curative therapies cannot be applied, and only systemic therapy is

This is an open access article distributed under the terms of the Creative Commons Attribution-NonCommercial-ShareAlike 3.0 License, which allows others to remix, tweak, and build upon the work non-commercially, as long as the author is credited and the new creations are licensed under the identical terms.

For reprints contact: service@oaepublish.com

How to cite this article: Zhang XH, Zhu Q, Li J, Huang L, Yan JJ, Xu F, Li $\mathrm{J}$, Yan YQ. Arterial blood supply of hepatocellular carcinoma is associated with efficacy of sorafenib therapy. Hepatoma Res 2016;2:87-91. 
available. ${ }^{[2]}$

Sorafenib is a multikinase inhibitor which inhibits angiogenesis by targeting the vascular endothelial growth factor (VEGF) receptor 2 and platelet-derived growth factor receptor pathway and blocks cell proliferation by targeting the Ras/mitogen-activated protein kinase signaling pathway. Two global phase III trials (SHARP ${ }^{[3]}$ and Asia-Pacific trial) ${ }^{[4]}$ showed that sorafenib prolonged the survival of patients with advanced HCC. Following that, multiple studies have been conducted to determine the predictor for survival in patients treated with sorafenib. There are some previous reports concerning the relationship between prognosis of patients treated with sorafenib and parameters of computed tomography (CT) scan and magnetic resonance imaging (MRI). ${ }^{[5-8]}$ Hahn et $a l^{[6]}$ showed that the area under the contrast concentration vs. time curve $90 \mathrm{~s}$ after contrast injection (IAUC90) and volume transfer constant of contrast agent [K (trans)] measured by MRI were prognostic pharmacodynamic biomarkers for metastatic renal carcinoma treated with sorafenib. In addition, Hsu et al. ${ }^{[7]}$ found $\mathrm{K}$ (trans) correlated well with tumor response and survival in HCC patients who received sorafenib plus metronomic tegafur/ uracil therapy. Sorafenib signif icantly suppressed tumor per fusion, tumor vascularity, and endothelial permeability-surface area product quantif ied by CT scan in experimental prostate carcinoma in rats. ${ }^{[5,9,10]}$ It seems that CT scan or MRI may be applicable for imaging biomarkers of therapy response to antiangiogenic therapy.

We present our monocentric experience with sorafenib in the treatment of HCC patients and will attempt to identify predictive factors for survival, by placing emphasis on the correlation of the results from imaging and survival.

\section{METHODS}

\section{Patients}

A total of 38 HCC patients treated from April 2009 to December 2010 with sorafenib were included in this study. Hypervascular HCCs were diagnosed by at least 2 radiologic imaging showing characteristic features of HCC (contrast enhancement on the arterial phase with venous washout), or 1 radiologic imaging showing characteristic features of HCC associated with alpha-fetoprotein (AFP) $\geq 400 \mathrm{ng} / \mathrm{mL}$, while hypovascular HCCs were diagnosed by biopsy with cytological or histological confirmation. Eligibility criteria also included Eastern Cooperative Oncology Group Performance Status of 0 or 1; Child-Pugh liver function class A. All eligible patients received continuous oral treatment with $400 \mathrm{mg}$ of sorafenib (consisting of two 200-mg tablets, provided by Bayer HealthCare Pharmaceuticals) twice daily. HCC is staged according to the Barcelona Clinic Liver Cancer (BCLC) classification. ${ }^{[1]}$ HCCs were divided into good arterial supply and poor arterial supply according to the enhancement intensity on CT scan or MRI and were assessed by an experienced radiologist who was blind to clinical information. Good arterial supply is defined as enhancement in $\geq 60 \%$ lesions while poor arterial supply is defined as enhancement in $\leq 40 \%$ lesions.

\section{Study design}

Our null hypothesis was that patients with a good arterial supply of tumors and those with a poor arterial supply of tumors benefitted similar outcomes. The primary endpoint of the trial was the 12-month overall survival (OS) rate. The secondary end points were the recurrence-free survival rate and the overall recurrence rate. Data were collected and stored in the liver cancer database management system by a designated clinical study center assistant chosen by the Research Ethics Committee.

This study met the requirements of the Declaration of Helsinki and was approved by the Research Ethics Committee of the Eastern Hepatobiliary Surgery Hospital, which is affiliated with the Second Military Medical University. Informed consent was obtained from all recruited patients.

\section{Follow-up}

Clinical examinations were performed for each patient, with laboratory assessment (routine tests of liver and kidney function and AFP) every month and imaging exams (chest X-ray and abdominal CT scan or MRI) every other month. A systemic nuclide scan was carried out when metastasis was suspected. Additional treatments, such as transarterial chemoembolization (TACE), were applied when necessary. Adverse events were under sur veillance, and proper managements were provided when necessary.

\section{Statistical analysis}

Quantitative data were expressed as a mean \pm standard deviation (SD) or median (range) where appropriate and compared using the independent sample $t$-test. For quantitative data, the gaussianity 
test was performed to test for homogeneity of variances. Homogeneous variances were indicated as a mean plus or minus SD (mean $\pm \mathrm{SD}$ ) and the Student's $t$-test was used for statistical analysis. If the variances were not homogeneous, they were presented as median in combination with the range. Categorical variables were compared using the Chi-square test with Yates correction or the Fisher exact test where appropriate. $P<0.05$ was considered significantly. Hazard ratios (HRs) and their corresponding $95 \%$ confidence interval (CI) were calculated using simple logistic-regression analysis.

Survival rates were obtained by the Kaplan-Meier method and were compared using the log-rank test. Cox regression model was used to analyze the prognostic predictors for survival. Survival time started from the date of treatment with sorafenib until death or the closing date. The closing date of this study was August 31, 2011.

\section{RESULTS}

\section{Baseline characteristics}

Among the 38 patients treated with sorafenib, mean age was $53.3 \pm 11.1$ years and $35(92.1 \%)$ were males. All the patients had viral hepatitis background, with a hepatitis B prevalence of $94.7 \%$. The baseline characteristics of the 38 patients are shown in Table 1. Tumors in 17 patients were classified as good arterial supply while the other patients belonged to poor arterial supply according to the judgment of the radiologist. A total of 30 patients received 1 time additional therapy of TACE during the period of follow-up, of which 13 patients with a good arterial supply of the tumors and 17 with poor arterial supply.

\section{Safety and adverse events}

Each patient experienced at least one adverse event in the duration of sorafenib administration. Handfoot skin reaction and diarrhea were the most common discomforts complained by the patients. Less common adverse effects included fatigue, alopecia, hypertension, and diabetes. A total of 6 patients had dose reduction due to severe adverse events, of which 3 for diarrhea and 3 for handfoot skin reaction. None of the patients had drug discontinuation.

\section{Survival analysis}

At the closing date of this study, 29 (76.3\%) patients died and 9 patients were still alive. The median survival time (MST) was 10.7 months $(95 \% \mathrm{Cl}, 8.7$ -
Table 1: Baseline characteristics of 38 patients included in the study

\begin{tabular}{|c|c|}
\hline Variable & $n=38$ \\
\hline Sex (male/female) & $35 / 3$ \\
\hline $\begin{array}{l}\text { Age (years) } \\
\text { ECOG PS }\end{array}$ & $53.3 \pm 11.1$ \\
\hline 0 & 32 \\
\hline 1 & 6 \\
\hline \multicolumn{2}{|l|}{$\mathrm{BCLC}$ stage } \\
\hline B & 18 \\
\hline C & 20 \\
\hline \multicolumn{2}{|c|}{ Arterial supply of the tumor } \\
\hline Good & 17 \\
\hline Poor & 21 \\
\hline \multicolumn{2}{|l|}{ Portal invasion } \\
\hline Yes & 14 \\
\hline No & 24 \\
\hline \multicolumn{2}{|l|}{ Extrahepatic metastasis } \\
\hline Yes & 9 \\
\hline Collaborative treatment & 29 \\
\hline $\begin{array}{l}\text { TACE } \\
\text { Collabortive treatment }\end{array}$ & 30 \\
\hline None & 8 \\
\hline \multicolumn{2}{|l|}{ Hepatitis background } \\
\hline Hepatitis B & 36 \\
\hline Hepatitis C & 2 \\
\hline \multicolumn{2}{|l|}{ Vascular thrombus } \\
\hline $\begin{array}{l}\text { Presence } \\
\text { Absence }\end{array}$ & $\begin{array}{l}12 \\
26\end{array}$ \\
\hline Tumor size & $8.1 \pm 3.1$ \\
\hline AFP (ng/mL) & $205.1(2-2,483,000)$ \\
\hline Total bilirubin (umol/L) & $15.0 \pm 7.6$ \\
\hline $\begin{array}{l}\text { Albumin (g/L) } \\
\text { Pre-albumin (mg/L) }\end{array}$ & $\begin{array}{c}39.3 \pm 4.6 \\
1440+460\end{array}$ \\
\hline ALT (IU/L) & $48.3 \pm 65.9$ \\
\hline AST (IU /L') & $55.3 \pm 49.3$ \\
\hline PT (s) & $12.5 \pm 1.1$ \\
\hline BUN' (mmol/L) & $5.43 \pm 0.69$ \\
\hline $\mathrm{Cr}(\mathrm{umol} / \mathrm{L})$ & $69.18 \pm 11.61$ \\
\hline
\end{tabular}

ECOG PS: Eastern Cooperative Oncology Group Performance Status; BCLC: Barcelona Clinic Liver Cancer; TACE: transarterial chemoembolization; AFP: alpha-fetoprotein; ALT: alanine aminotransferase; AST: aspartate aminotransferase; PT: prothrombin time; BUN: blood urea nitrogen; Cr: creatinine

12.7) and the 1-year OS was $41.0 \%$. On univariate analysis [Table 2], the MST and 1-year OS in patients with good arterial supply of tumors were 12 months (range: 4-20 months) and 52.9\%, compared with that of 7 months (range: 1-16 months) and $23.8 \%$ in patients with poor arterial supply of tumors $(P=$ 0.002). Similarly, patients who had tumors at BCLC stage B had longer MST and higher OS than those who had tumors at BCLC stage C. However, there was no statistically significant difference between these two stages.

Eight variables were selected on multivariate analysis to determine the prognostic predictors for survival in patients treated with sorafenib [Table 3]. Only arterial supply of the tumors remained statistically predictive for OS (HR: $0.22,95 \% \mathrm{CI}, 0.07-0.67, P=$ 0.008).

\section{DISCUSSION}

As a highly vascularized neoplasm, most HCCs exert imaging characteristics of intense contrast uptake in the arterial phase, followed by contrast washout in the delayed venous phase at dynamic imaging by 
Table 2: Univariate analysis of factors associated with survival of patients included in the study

\begin{tabular}{|c|c|c|c|c|}
\hline & $n$ & $\begin{array}{c}\text { Median } \\
\text { survival time } \\
\text { (months) }\end{array}$ & $\begin{array}{c}\text { 1-year } \\
\text { survival } \\
\text { rate (\%) }\end{array}$ & $\begin{array}{c}\text { Log-rank } \\
\text { test } \\
P \\
\end{array}$ \\
\hline $\begin{array}{l}\text { BCLC stage } \\
\text { B }\end{array}$ & 18 & $12.5(2-18)$ & 61.1 & 0.067 \\
\hline $\begin{array}{l}\text { Arterial supply of } \\
\text { the tumors }\end{array}$ & 20 & $7.5(1-20)$ & 15.0 & \\
\hline $\begin{array}{l}\text { Good } \\
\text { Poor }\end{array}$ & $\begin{array}{l}17 \\
21\end{array}$ & $\begin{array}{l}12(4-20) \\
7(1-16)\end{array}$ & $\begin{array}{l}52.9 \\
23.8\end{array}$ & 0.002 \\
\hline Portal invasion & & & & \\
\hline $\begin{array}{l}\text { Yes } \\
\text { No }\end{array}$ & $\begin{array}{l}14 \\
24\end{array}$ & $\begin{array}{c}8.5(1-19) \\
11.5(2-20)\end{array}$ & $\begin{array}{l}21.4 \\
50.0\end{array}$ & 0.206 \\
\hline $\begin{array}{l}\text { Extrahepatic } \\
\text { metastasis }\end{array}$ & & & & \\
\hline Yes & 9 & $9(2-20)$ & 22.2 & 0.591 \\
\hline $\begin{array}{l}\text { No } \\
\text { Collaborative } \\
\text { treatment }\end{array}$ & 29 & $10(1-18)$ & & \\
\hline TACE & 30 & $10(1-19)$ & 40.0 & 0.504 \\
\hline $\begin{array}{l}\text { None } \\
\text { AFP }\end{array}$ & 8 & $8(2-20)$ & 25.0 & \\
\hline $\begin{array}{l}\geqslant 400 \mathrm{ng} / \mathrm{mL} \\
<400 \mathrm{ng} / \mathrm{mL}\end{array}$ & $\begin{array}{l}15 \\
23\end{array}$ & $\begin{array}{l}8.5(2-18) \\
11(1-20)\end{array}$ & $\begin{array}{l}20.0 \\
47.8\end{array}$ & 0.347 \\
\hline Albumin & & & & \\
\hline $\begin{array}{l}>\text { ULN } \\
\leqslant \text { ULN }\end{array}$ & $\begin{array}{l}12 \\
26\end{array}$ & $\begin{array}{c}9.5(4-19) \\
9(1-20)\end{array}$ & $\begin{array}{l}41.7 \\
34.6\end{array}$ & 0.159 \\
\hline ALT & & & & \\
\hline $\begin{array}{l}>\text { ULN } \\
\leqslant \text { ULN }\end{array}$ & $\begin{array}{l}12 \\
26\end{array}$ & $\begin{array}{l}13(1-20) \\
9(2-19)\end{array}$ & $\begin{array}{l}58.3 \\
35.0\end{array}$ & 0.063 \\
\hline AST & & & & \\
\hline $\begin{array}{l}>\text { ULN } \\
\leqslant \text { ULN }\end{array}$ & $\begin{array}{l}18 \\
20\end{array}$ & $\begin{array}{l}9(2-18) \\
10(1-20)\end{array}$ & $\begin{array}{l}38.9 \\
35.0\end{array}$ & 0.881 \\
\hline
\end{tabular}

BCLC: Barcelona Clinic Liver Cancer; TACE: transarterial chemoembolization; AFP: alpha-fetoprotein; ULN: upper limit of normal; ALT: alanine aminotransferase; AST: aspartate aminotransferase

Table 3: Multivariate Cox's model for factors associated with survival of patients included in the study

\begin{tabular}{lccc}
\hline Variable & HR & $95 \%$ Cl for HR & $P$ \\
\hline BCLC stage (B vs. C) & 0.33 & $1.29-10.53$ & 0.335 \\
Portal invasion (yes vs. no) & 1.15 & $0.19-7.03$ & 0.881 \\
Extrahepatic metastasis (yes vs. no) & 0.88 & $0.13-5.94$ & 0.893 \\
Arterial supply of the tumor (good vs. poor) & 0.21 & $0.07-0.67$ & 0.008 \\
Collaborative treatment (TACE vs. none) & 1.54 & $0.48-4.91$ & 0.470 \\
AFP ( $\geqslant 400$ ng/m vs. $<400$ ng/m) & 1.33 & $0.50-3.49$ & 0.568 \\
Albumin $>$ ULN vs. $\leqslant$ ULN) & 2.13 & $1.00-6.50$ & 0.064 \\
ALT $>$ ULN vs. $\leqslant$ ULN) & 0.35 & $0.11-1.08$ & 0.068 \\
AST $>$ ULN vs. $\leqslant$ ULN) & 1.05 & $0.37-2.98$ & 0.925
\end{tabular}

HR: hazard ratio; Cl: confidence interval; BCLC: Barcelona Clinic Liver Cancer; TACE: transarterial chemoembolization; AFP: alpha-fetoprotein; ULN: upper limit of normal; ALT: alanine aminotransferase; AST: aspartate aminotransferase

contrast-enhanced CT scan or gadolinium-enhanced MRI. ${ }^{[1]}$ However, there are also many HCCs, which display poor contrast enhancement on CT scan or MRI on the arterial phase.

In this study, when we concentrated on the relationship between the degree of enhancement on the arterial phase of CT scan/MRI and the prognosis of HCC patients treated with sorafenib, the results showed that patients with good arterial supply benefitted more than those with poor arterial supply. Previously, Li et al. ${ }^{[12]}$ and Ippolito et al. ${ }^{[13]}$ found that CT scan could provide quantitative information about tumor-related angiogenesis, which could be used to assess tumor vascularization. During hepatocarcinogenesis, arterial and portal blood flow would decrease, and then new arterial vessels formatted because of the reduced arterial blood flow. And this caused hypervascular lesions to occur. ${ }^{[14,15]}$ The degree of tumor enhancement on the arterial phase could be an important symbol of vascularization. Neovascularization played a critical role during growth of solid neoplasms, ${ }^{[16]}$ and VEGF played an important role in regulating angiogenesis and endothelial cell proliferation. ${ }^{[17]}$ In the past few years, several studies had shown that the VEGF expression in HCC was correlated with imaging findings. ${ }^{[18-21]} \mathrm{Kwak}$ et al. ${ }^{[21]}$ found that the strong arterial enhancement of HCC resulted from a strong VEGF expression which was responsible for an increased vascular permeability and increased proliferation of the endothelial cells. In contrast, sorafenib inhibited the activity of VEGF receptors and other proangiogenic signaling pathways. In mouse xenograft models of HCC, sorafenib significantly reduced tumor microvessel density. These observations, combined with the relatively short half-life of sorafenib, suggest that sorafenib administered during and after TACE treatment may counteract hypoxia-induced angiogenesis and potentially yield synergistic efficacy in decreasing tumor burden. However, these hypothesis generated findings remain speculative until sufficient clinical trial data can be accumulated.

It is reported that there is a significant correlation between efficacy of sorafenib administered combined with TACE treatment and arterial blood supply of HCC. According to our study, the stronger the enhancement intensity of HCCs on the arterial phase, the longer the HCC patients treated with sorafenib survived. Maybe the level of VEGF could indicate the treatment effect of sorafenib, and further research needs to be done to reveal the correlation between the VEGF activity and efficacy of sorafenib.

The major limitations of this study are the noncomparative design and a limited number of patients. A prospective study should be done to investigate the correlation between enhancement intensity of HCCs in the arterial phase and survival of HCC patients treated with sorafenib.

In conclusion, arterial blood supply is an independent predictor for survival in patients treated with sorafenib, and patients with a good arterial supply of 
tumors benefit more than those with a poor arterial supply of tumors. Further prospective studies need to be conducted to reveal the relationship between the degree of tumor enhancement in the arterial phase and the prognosis of HCC patients treated with sorafenib therapy.

\section{Financial support and sponsorship}

This work is supported by Second Military Medical University Funds for Young Scholar (2011QN23) and National Natural Science Foundation (81301878).

\section{Conflicts of interest}

There are no conflicts of interest.

\section{REFERENCES}

1. Forner A, Llovet JM, Bruix J. Hepatocellular carcinoma. Lancet 2012;379:1245-55.

2. El-Serag HB, Marrero JA, Rudolph L, Reddy KR. Diagnosis and treatment of hepatocellular carcinoma. Gastroenterology 2008:134:1752-63.

3. Llovet JM, Ricci S, Mazzaferro V, Hilgard P, Gane E, Blanc JF, de Oliveira AC, Santoro A, Raoul JL, Forner A, Schwartz M, Porta C, Zeuzem S, Bolondi L, Greten TF, Galle PR, Seitz JF, Borbath I, Häussinger D, Giannaris T, Shan M, Moscovici M, Voliotis D, Bruix J; SHARP Investigators Study Group. Sorafenib in advanced hepatocellular carcinoma. $N$ Engl J Med 2008;359:378-90.

4. Cheng AL, Kang YK, Chen Z, Tsao CJ, Qin S, Kim JS, Luo R, Feng J, Ye S, Yang TS, Xu J, Sun Y, Liang H, Liu J, Wang J, Tak WY, Pan H, Burock K, Zou J, Voliotis D, Guan Z. Efficacy and safety of sorafenib in patients in the Asia-Pacific region with advanced hepatocellular carcinoma: a phase III randomised, double-blind, placebo-controlled trial. Lancet Oncol 2009;10:25-34.

5. Cyran CC, von Einem JC, Paprottka PM, Schwarz B, Ingrisch M, Dietrich O, Hinkel R, Bruns CJ, Clevert DA, Eschbach R, Reiser MF, Wintersperger BJ, Nikolaou K. Dynamic contrast-enhanced computed tomography imaging biomarkers correlated with immunohistochemistry for monitoring the effects of sorafenib on experimental prostate carcinomas. Invest Radiol 2012;47:49-57.

6. Hahn OM, Yang C, Medved M, Karczmar G, Kistner E, Karrison T, Manchen E, Mitchell M, Ratain MJ, Stadler WM. Dynamic contrastenhanced magnetic resonance imaging pharmacodynamic biomarker study of sorafenib in metastatic renal carcinoma. $J$ Clinl Oncol 2008;26:4572-8.

7. Hsu CY, Shen YC, Yu CW, Hsu C, Hu FC, Hsu CH, Chen BB, Wei SY, Cheng AL, Shih TT. Dynamic contrast-enhanced magnetic resonance imaging biomarkers predict survival and response in hepatocellular carcinoma patients treated with sorafenib and metronomic tegafur/ uracil. J Hepatol 2011;55:858-65.

8. Flaherty KT, Rosen MA, Heitjan DF, Gallagher ML, Schwartz B, Schnall MD, O'Dwyer PJ. Pilot study of DCE-MRI to predict progression-free survival with sorafenib therapy in renal cell carcinoma. Cancer Biol Ther 2008; 7:496-501.

9. Horger M, Lauer UM, Schraml C, Berg CP, Koppenhöfer U, Claussen $\mathrm{CD}$, Gregor M, Bitzer M. Early MRI response monitoring of patients with advanced hepatocellular carcinoma under treatment with the multikinase inhibitor sorafenib. BMC Cancer 2009;9:208.

10. Lewin M, Fartoux L, Vignaud A, Arrivé L, Menu Y, Rosmorduc O. The diffusion-weighted imaging perfusion fraction $\mathrm{f}$ is a potential marker of sorafenib treatment in advanced hepatocellular carcinoma: a pilot study. Eur Radiol 2011;21:281-90.

11. Marrero JA. Staging systems for hepatocellular carcinoma: should we all use the BCLC system? J Hepatol 2006;44:630-2.

12. Li JP, Zhao DL, Jiang HJ, Huang YH, Li DQ, Wan Y, Liu XD, Wang JE. Assessment of tumor vascularization with functional computed tomography perfusion imaging in patients with cirrhotic liver disease. Hepatobiliary Pancreat Dis Int 2011;10:43-9.

13. Ippolito D, Sironi S, Pozzi M, Antolini L, Ratti L, Alberzoni C, Leone EB, Meloni F, Valsecchi MG, Fazio F. Hepatocellular carcinoma in cirrhotic liver disease: functional computed tomography with perfusion imaging in the assessment of tumor vascularization. Acad Radiol 2008;15:919-27.

14. Asayama Y, Yoshimitsu K, Nishihara Y, Irie H, Aishima S, Taketomi A, Honda H. Arterial blood supply of hepatocellular carcinoma and histologic grading: radiologic-pathologic correlation. AJR Am J Roentgenol 2008;190:W28-34.

15. Tajima T, Honda H, Taguchi K, Asayama Y, Kuroiwa T, Yoshimitsu K, Irie H, Aibe H, Shimada M, Masuda K. Sequential hemodynamic change in hepatocellular carcinoma and dysplastic nodules: CT angiography and pathologic correlation. AJR Am J Roentgenol 2002;178:885-97.

16. Folkman J. Tumor angiogenesis: therapeutic implications. $N$ Engl $J$ Med 1971;285:1182-6.

17. Senger DR, Van De Water L, Brown LF, Nagy JA, Yeo KT, Yeo TK, Berse B, Jackman RW, Dvorak AM, Dvorak HF. Vascular permeability factor (VPF, VEGF) in tumor biology. Cancer Metastasis Rev 1993;12:303-24

18. Von Marschall Z, Cramer T, Höcker M, Finkenzeller G, Wiedenmann B, Rosewicz S. Dual mechanism of vascular endothelial growth factor upregulation by hypoxia in human hepatocellular carcinoma. Gut 2001;48:87-96.

19. Kanematsu M, Osada S, Amaoka N, Goshima S, Kondo H, Nishibori H, Kato H, Matsuo M, Yokoyama R, Hoshi H, Moriyama N. Expression of vascular endothelial growth factor in hepatocellular carcinoma and the surrounding liver: correlation with angiographically assisted CT. AJR Am J Roentgenol 2004;183:1585-93.

20. Suzuki K, Hayashi N, Miyamoto Y, Yamamoto M, Ohkawa K, Ito Y, Sasaki Y, Yamaguchi Y, Nakase H, Noda K, Enomoto N, Arai K, Yamada Y, Yoshihara H, Tujimura T, Kawano K, Yoshikawa K, Kamada T. Expression of vascular permeability factor/vascular endothelial growth factor in human hepatocellular carcinoma. Cancer Res 1996;56:3004-9.

21. Kwak BK, Shim HJ, Park ES, Kim SA, Choi D, Lim HK, Park CK, Chung JW, Park JH. Hepatocellular carcinoma: correlation between vascular endothelial growth factor level and degree of enhancement by multiphase contrast-enhanced computed tomography. Invest Radiol 2001;36:487-92. 